\title{
LEAD FAILURE CAUSED BY TWIDDLER'S SYNDROME IN SUBPECTORALLY IMPLANTED UNIPOLAR SINGLE-LEAD CARDIOVERTER-DEFIBRILLATORS
}

Christian Mewis, MD, ${ }^{a}$ Volker Kühlkamp, MD, ${ }^{a}$ Volker Dörnberger, $\mathrm{MD},{ }^{a}$ Koroush Kalighi, MD, ${ }^{\mathrm{b}}$ and

Ludger Seipel, MD, ${ }^{\text {a }}$ Tübingen, Germany

Twiddler's syndrome, first described in 1968 by Bayless, Beanlands, and Baird ${ }^{1}$ as a rare complication in patients with pacemakers, is characterized by dislodgment of transvenous leads by the twisting of pulse generators in the subcutaneous pocket, resulting in lead malfunction. As might be expected, similar complications could arise in the case of subpectorally placed implantable cardioverterdefibrillators (ICDs). Especially in unipolar defibrillation systems, which use the housing of the ICD itself as the second active defibrillation electrode, device migration could have a fatal influence on the defibrillation field. We report two cases of this rare complication.

PATIENT 1. A 66-year-old male patient (body index 24.5 $\mathrm{kg} / \mathrm{m}^{2}$ ) with severe coronary artery disease and ventricular tachycardia was referred to our clinic. Bypass surgery was

From the Departments of Cardiology and Cardiothoracic Surgery, ${ }^{\mathrm{b}}$ University Hospital Tübingen, Tübingen, Germany.

Received for publication May 6, 1997; accepted for publication June 24, 1997.

Address for reprints: Christian Mewis, MD Department of Cardiology, University Hospital Tübingen, Otfried-MüllerStr. 10, 72076 Tübingen, Germany.

J Thorac Cardiovase Surg 1997;114:1121-2

Copyright $(\mathcal{C} 1997$ by Mosby-Year Book, Inc. $0022-5223 / 97 \$ 5.00+0 \quad \mathbf{1 2 / 5 4 / 8 4 3 0 0}$ performed. Three weeks later, after full recovery, programmed ventricular stimulation induced sustained monomorphic ventricular tachycardia. An ICD (Jewel Plus 7220 active can, $80 \mathrm{~cm}^{2}, 129 \mathrm{gm}$; Medtronic, Inc., Minneapolis, Minn.) was implanted with a unipolar single lead (Transvene 6936, length $65 \mathrm{~cm}$; Medtronic, Inc.) positioned in the right ventricle because drug testing failed to suppress the ventricular tachycardia.

A skin incision was performed parallel and approximately $2 \mathrm{~cm}$ inferior to the left clavicle. A subpectoral pocket was created by bluntly separating the transverse muscle fibers of the pectoralis major muscle that insert in the clavicle and sternum. Thereafter, the patient stayed well without any shock deliveries for 3 months. At the routine 3-month visit, an exit block of the pacing lead with an increased impedance to $1366 \Omega$ was noted. The patient did not report any device manipulation, local discomfort, or excessive device mobility. Surgical exploration of the ICD pocket revealed a ninefold twirling of the pulse generator around its longitudinal axis (Fig. 1), causing a tight twisting of the electrode near the aggregate. The intraoperative defibrillation threshold of $9 \mathrm{~J}$ was unchanged from the initial one. The pulse generator was disconnected and removed, and the lead was untwisted and replaced with a new lead. The generator was reimplanted in a pocket more medial than the former one and also anchored at the underlying muscle fascia. Twelve

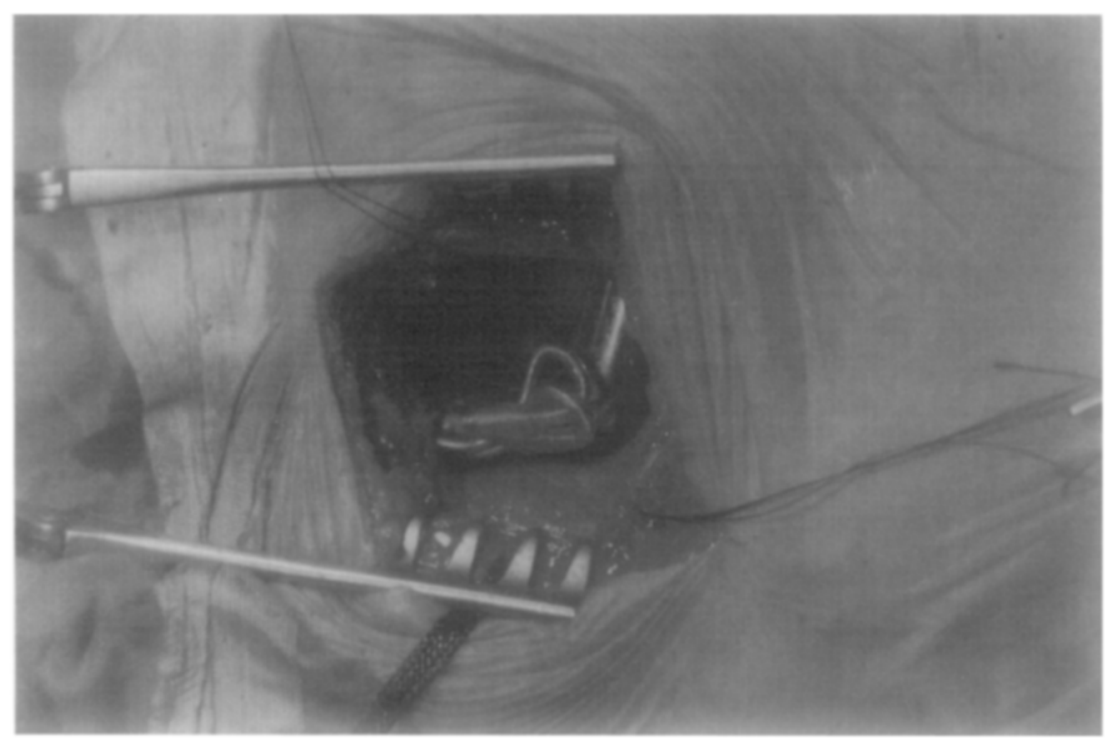

Fig. 1. The intraoperative situs of patient 1 revealed the twisted lead near the aggregate. On further exploration, the pulse generator was seen to have twirled nine times around its longitudinal axis. 
months later, chest radiography showed a stable generator position.

PATIENT 2. In a 59-year-old obese male patient (body index $33.5 \mathrm{~kg} / \mathrm{m}^{2}$ ) with aborted cardiac arrest and dilated cardiomyopathy, a unipolar ICD (Ventak Mini 1742 HC, $125 \mathrm{gm}$, volume $68 \mathrm{~cm}^{2}$; Cardiac Pacemakers, Inc., St. Paul) was implanted in left subpectoral position with a tripolar silicone lead (Endotak CR 0125, length $70 \mathrm{~cm}$; Cardiac Pacemakers, Inc.) in the apex of the right ventricle. The implantation technique was performed as described for patient 1 . Three months later, patient 2 had a routine visit to our outpatient clinic. In the meantime, he had lost approximately $8 \mathrm{~kg}$ weight. The test of the ICD revealed a rise in the pacing threshold of $5 \mathrm{~V}$, with impulse width of $0.6 \mathrm{msec}$. The remaining parameters, including the defibrillation threshold, were unchanged from the values of the predischarge test. Surgical exploration showed a laterally dislocated pulse generator that was rotated 22 times around its longitudinal axis in a loose, subpectoral pocket. The lead was disconnected, untwisted, and removed. The pocket was plicated, and the generator was anchored with sutures at the underlying muscle fascia to prevent further generator movements. A new lead was inserted. The patient was discharged, and follow-up 6 months later showed a stable function and position of the device.

Discussion. The twiddler's syndrome may remain asymptomatic as in these cases, but lead fracture or dislodgement in an ICD can cause inadequate shock deliveries or even sudden cardiac death. ${ }^{2}$ This syndrome has been described in some patients with abdominal ICDs $^{3}$ and 5 weeks after implantation in one patient with an ICD in subpectoral position who palpated his pulse generator for hours at time because of moderate discomfort. ${ }^{4}$ To our knowledge, these two cases of twiddler's syndrome are the first reported with unipolar devices. In this type of ICD, the defibrillation field depends on a stable position of the shell. The defibrillation threshold thus could increase significantly with device migration. In our cases, however, the defibrillation threshold remained stable. This may be because the devices migrated mainly laterally and not in the longitudinal axis, influencing the defibrillation field less. In both cases, the implantation technique was as generally recommended.5 However, these two patients may have had predisposing factors for increased device mobility. Patient 1's long period of hospitalization caused atrophy of both pectoralis muscles, which may have contributed to an increased generator mobility. In the case of patient 2 , obesity was a risk factor for device mobility. Furthermore, this patient lost significant weight after ICD implantation, which may have caused a loose generator pocket. In both cases, suturing of the generator to the underlying muscle fascia led to sufficient device stability.

Increasing numbers of this complication of subpectorally implanted ICDs must be expected, because the devices are still larger and heavier than modern pacemakers. The use of the Parsonnet pouch, as suggested by Furman, ${ }^{6}$ may be effective in preventing twiddler's syndrome in patients with risk factors such as obesity or pectoral atrophy.

\section{REFERENCES}

1. Bayless CE, Beanlands DS, Baird RJ. The pacemaker-twiddler's syndrome: a new complication of implantable transvenous pacemakers. Can Med Assoc J 1968;99:371-3.

2. Avitall B, Stormo A, Barragry T, Axtel K, Hare J. Sudden cardiac death: twiddler's syndrome with an implantable cardioverter defibrillator. Am Heart J 1994;128:833-6.

3. Robinson LA, Windle JR. Defibrillator twiddler's syndrome. Ann Thorac Surg 1994;58:247-9.

4. Crossley GH, Gayle DD, Bailey JR, Haisty WK, Simmons TW, Fitzgerald DM. Defibrillator twiddler's syndrome causing device failure in a subpectoral transvenous system. PACE Pacing Clin Electrophysiol 1996;19:376-7.

5. Foster AH. Technique for implantation of cardioverter defibrillators in the subpectoral position. Ann Thorac Surg 1995; 59:764-7.

6. Furman S. Defibrillator twiddler's syndrome. Ann Thorac Surg 1995;59:544-6. 